\title{
Emission factors and environmental implication of organic pollutants in PM emitted from various vessels in China
}

\author{
Fan Zhang ${ }^{\mathrm{a}, \mathrm{b}}$, Yingjun Chen ${ }^{\mathrm{c}, *}$, Min Cui ${ }^{\mathrm{a}, \mathrm{b}}$, Yanli Feng ${ }^{\mathrm{d}}$, Xin Yang $^{\mathrm{c}}$, Jianmin Chen ${ }^{\mathrm{c}}$, Yan Zhang ${ }^{\mathrm{c}}$, \\ Huiwang Gao ${ }^{\mathrm{e}, \mathrm{f}}$, Chongguo Tian ${ }^{\mathrm{g}}$, Volker Matthias ${ }^{\mathrm{h}}$, Huan $\mathrm{Liu}^{\mathrm{i}, * *}$ \\ ${ }^{a}$ Key Laboratory of Cities' Mitigation and Adaptation to Climate Change in Shanghai, China Meteorological Administration, Tongji University, Shanghai, o0o92, PR China \\ b, State Key Laboratory of Pollution Control and Resource Reuse, College of Environmental Science and Engineering, Tongji University, Shanghai, O0092, PR China \\ ' Shanghai Key Laboratory of Atmospheric Particle Pollution and Prevention (LAP3), Department of Environmental Science and Engineering, Fudan University, Shanghai, \\ 200092, PR China \\ ${ }^{\mathrm{d}}$ Institute of Environmental Pollution and Health, School of Environmental and Chemical Engineering, Shanghai University, Shanghai, 200444, PR China \\ ${ }^{\mathrm{e}}$ Key Laboratory of Marine Environment and Ecology, Ocean University of China, Ministry of Education of China, Qingdao, PR China \\ ${ }^{\mathrm{f}}$ Laboratory for Marine Ecology and Environmental Sciences, Qingdao National Laboratory for Marine Science and Technology, Qingdao, 266071, PR China \\ ${ }^{\mathrm{g}}$ Key Laboratory of Coastal Environmental Processes and Ecological Remediation, Yantai Institute of Coastal Zone Research, Chinese Academy of Sciences, Yantai, \\ Shandong, 264003, PR China \\ ${ }^{\mathrm{h}}$ Helmholtz-Zentrum Geesthacht, Institute of Coastal Research, Max-Planck-Straße 1, 21502, Geesthacht, Germany \\ ${ }^{i}$ State Key Joint Laboratory of ESPC, School of the Environment, Tsinghua University, Beijing, 100084, PR China
}

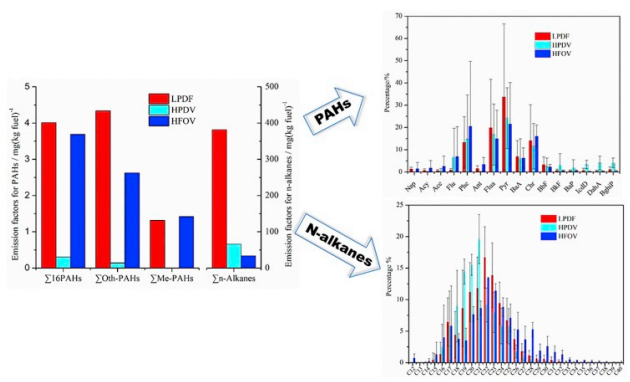

A R T I C L E I N F O

\section{Keywords:}

Emission factor

Organic pollutants

PM

Vessel

Environmental implication

\begin{abstract}
A B S T R A C T
Organic pollutants from ship exhaust have significant health and air quality impact in coastal areas; their profiles are also in urgent need. Studies on organic pollutants from ships are still rare, especially in China. Therefore, 21 PAHs and 29 n-alkanes in PM emitted from 15 ships with different types and fuels under different operating modes in China were tested in this study. The results showed that: (1) Identified organic matters accounted for $0.15 \%-23.3 \%$ of PM. Fuel-based emission factors (EFs) for $\Sigma 16 \mathrm{PAHs}$ ranged from 0.095 to $5.80 \mathrm{mg}\left(\mathrm{kg}\right.$ fuel) ${ }^{-1}$, with low-engine-power fishing boats and heavy fuel oil (HFO) training ship had higher values compared with light diesel vessels. EFs for $\Sigma$ n-alkanes ranged from 5.22 to $1589 \mathrm{mg}$ (kg fuel) ${ }^{-1}$, with low-engine-power fishing boats had higher values compared with other vessels. (2) The dominant PAHs were medium molecular weight components of Pyr, Flua, Phe, and Chr. N-alkanes from C15 to C33 accounted for more than 97\% of the total nalkanes. (3) Ratios of typical PAHs and n-alkanes parameters in this study showed typical diagnostic characteristics of oil combustion source. Profiles and diagnostic characteristics of PAHs together with n-alkanes could
\end{abstract}

\footnotetext{
* Corresponding author.

** Corresponding author.

E-mail addresses: yjchentj@tongji.edu.cn (Y. Chen), liu_env@tsinghua.edu.cn (H. Liu).
} 
provide a more precise source apportionment result in the future. (4) Besides, PAHs in PM emitted from ships inferred non-ignorable health influence.

\section{Introduction}

Pollutants emitted from shipping emissions have gained more and more attentions in recent decades due to their significant impact on human health, air quality and climate change (Corbeet, 1997; Diesch et al., 2013; Eyring et al., 2010; Fuglestvedt et al., 2009; Hassellov et al., 2013; Jonson et al., 2009; Lack and Corbett, 2012; Liu et al., 2016; Schreier et al., 2006; Viana et al., 2014; Winebrake et al., 2009). As one of the most watched pollutants, particulate matter (PM), especially fine $\mathrm{PM}\left(\mathrm{PM}_{2.5}\right)$ account for non-ignorable proportions to primary $\mathrm{PM}_{2.5}$ in harbor or offshore areas, such as $2.4-3.3 \%$ in Venice (Gregoris et al., 2016), 3.1\% in Tianjin (Chen et al., 2016), 4.23\% in Shanghai (Zhao et al., 2013), 5-10\% in Bay of Algeciras (Pandolfi et al., 2011), $8.8 \%$ in West Long Beach Harbor. If secondary contribution is considered, it can reach very high proportions, such as $20-30 \%$ in Shanghai (Liu et al., 2017), 17\% in Bay of Algeciras (Pandolfi et al., 2011). Pollutants emitted from land-based sources are gradually decreasing due to the implementation of more advanced emission reduction technologies (e.g., on-road diesel engines) in recent years. The relative impact of shipping emissions is increasing, especially in coastal areas. In comparison to on-road vehicles, the emission characteristics from maritime vehicles are still poorly known. Chemical compositions such as heavy metal elements, OC (organic carbon), BC (black carbon) and other soluble elements of PM from shipping emissions are mainly concerned (Agrawal et al., 2008; Lack and Corbett, 2009; Diesch et al., 2013; Anderson et al., 2015; Celo et al., 2015; Zhang et al., 2016, 2018). Only limited studies have mentioned the organic compounds in PM (Agrawal et al., 2008, 2010; Cooper, 2003; Cooper et al., 1996; Crimmins et al., 2004; Sippula et al., 2014).

Polycyclic aromatic hydrocarbons (PAHs), a typical class of persistent organic pollutants, are ubiquitous in the environment. Due to their characteristics of toxicity, persistence, carcinogenicity, and mutagenicity (Srogi, 2007), the sources and distributions of PAHs have received more attention. The US Environmental Protection Agency (EPA) has promulgated 16 unsubstituted PAHs (EPA-PAH) as priority pollutants in 1970s (U.S. EPA., 1979). Vehicular emission is recognized as one of the most significant sources of PAHs. Moreover, particle-bound PAHs are considered to be a significant hazardous substance to human health through breathing (Srogi, 2007). Diagnostic ratios of PAHs can be used as potential special tracers when contribution of shipping emissions on atmosphere is calculated (Czech et al., 2017). N-alkanes are ubiquitous species that can suit to trace the origin and fate of different samples because of their relatively stable characteristics in the environment (Pietrogrande et al., 2010). The number of terms and the abundance distribution of the odd/even terms in the series are the two particular relevance parameters in describing n-alkane properties, which can determine the biogenic and anthropogenic sources, even fossil fuel source (Bray and Evans, 1961). Besides, Detailed PAHs and alkanes profiles are the basis to give more precise results of source apportionment of ambient PM. Therefore, studies on emission factors and characteristics of PAHs and alkanes from ships are in urgent need.

Shipping emissions in China have gained more and more attentions over the last decade due to the negligible total pollutant emission and their influence on atmosphere. However, most of the studies are focusing on emission inventories but based on data from other countries and areas (Chen et al., 2017; Fan et al., 2016; Fu et al., 2012; Jin et al., 2009; Li et al., 2016a; Song, 2014; Yang et al., 2015a, 2015b; Ye et al., 2014; Zhang et al., 2010); contributions of shipping emissions to harbor cities and areas (Zhang et al., 2014; Zhao et al., 2013). Only several studies have carried out onboard experimental test to give emission factors and characteristics of pollutants from ships in China (Fu et al., 2013; Peng et al., 2016; Song, 2015; Xiao et al., 2018; Zhang et al., 2016, 2018), which is the basis of emission inventory estimation and source apportionment. However, almost all of the studies are focusing on gaseous matters, PM and its main components such as OC, EC, water-soluble ions and elements, but no organic matters. Emission factors and profiles for organic matters emitted from vessels in China are in urgent need, not only for inventory estimation, but also for more precise source apportionment results of ambient PM.

In this study, organic compounds including 21 PAHs, 29 n-alkanes from $\mathrm{C} 12$ to $\mathrm{C} 40$ in PM were analyzed from 15 offshore vessels in China. (1) Emission factors and profiles of PAHs and alkanes of these vessels were given; (2) Diagnostic characteristics of PAHs and n-alkanes in PM from vessels in this study and other sources were discussed; (3) Potential toxicity risk assessment of PAHs in PM emitted from vessels were estimated, comparison with other sources were investigated.

\section{Material and methods}

\subsection{Test vessels and fuels}

PM samples from 15 different kinds of vessels were obtained in this study, including 11 fishing boats, 1 engineering ship, 2 research ships and 1 training ship, whose technical parameters are shown in Table A1. Detailed information of the tested vessels were introduced in previous studies (Zhang et al., 2016, 2018) except for the training vessel (YK), which is a typical HFO-ship. As introduced before, fishing boats, high speed diesel engine power vessels are the most important and negligible ships in offshore area in China. While YK is a typical heavy fuel oil ocean-going vessel, which can give representative emission data of HFO-ship in China. The sampling systems used in this study were two combined on-board emission test systems that were introduced in our previous studies (Zhang et al., 2016, 2018). The sampling system applied for YK was the same diluted system used for the fishing boats (Zhang et al., 2018).

The fuels used for the test vessels were different kinds of diesel fuels and heavy fuel oils. Table A2 presents the quality analysis results of the fuels. Main elements such as carbon (C), hydrogen (H), oxygen (O), nitrogen $(\mathrm{N})$ and sulfur $(\mathrm{S})$ were analyzed; other parameters were also analyzed in this study such as calorific values and some important metal elements. Detailed information of the heavy fuel oil used for YK was added in this study, other fuels had been introduced in previous studies (Zhang et al., 2016, 2018).

\subsection{Samples}

A total of 59 PM samples emitted from the 15 test vessels were chosen in this study, main operating modes of each vessel were included (seen in Table A3). According to actual operating modes, 3-6 PM samples were chosen for each vessel, which could represent the actual emission conditions.

\subsection{Chemical analysis and data analysis}

Sixteen priority PAHs, as indicated by US EPA, several Methyl substituted PAHs, and N-alkanes from C12 to C40 were detected in this study (seen in Table A4). The detailed chemical analysis method was introduced in section A1 of Supporting Information.

The carbon balance formula was used to calculate the EFs for all exhaust components in this study that was introduced in previous study 
(Zhang et al., 2016). Average emission factors for 21 PAHs and $29 \mathrm{n}$ alkanes in PM of each vessel were calculated according to actual operating condition in this study, which was the same method used in previous studies (Zhang et al., 2016, 2018).

\subsection{Quality assurance/quality control}

Rigorous quality assurance and control were conducted during the whole experiment. Filter blanks, reagent blanks were analyzed in the same way as mentioned above to determine any background concentration. Duplicate samples as well as standard samples were examined after analyzing a batch of 10 samples to ensure that the error was within $5 \%$. Five PAH surrogates and four n-alkane surrogates were added to each sample to assess the overall analytical procedure and recoveries. The average recoveries of the surrogates ranged from $66.7 \%$ to $128 \%$ in this study. The results of each sample were subtracted filter blank results. The final data reported in this research were not corrected by the recoveries.

\section{Results and discussions}

\subsection{Particle emissions and their composition}

Detailed fuel-based emission factors of PM and their chemical composition, including OC, EC, water-soluble ions, and metal elements, emitted from all the test vessels except the HFO training ship (YK) were introduced and discussed in our previous studies (Zhang et al., 2016, 2018). Combined with the data from YK, a general discussion and comparison of PM EFs and their main chemical compositions from all the vessels were given in this study (seen in Table A5). The test vessels in this study were divided into three categories according to engine power and fuel type, which were low-power-diesel fishing boat (LPDF), high-power-diesel vessel (HPDV), and HFO vessel (HFOV) (seen in Fig. 1). The PM EFs varied between 0.16 and $17.2 \mathrm{~g}$ (kg fuel) ${ }^{-1}$ for all the test vessels. Among the different types of vessels, LPDF had much higher PM emission factors of 7.73-17.2 $\mathrm{g}\left(\mathrm{kg}\right.$ fuel) ${ }^{-1}$, which might be caused by the high-speed engine used that usually had relatively lower combustion efficiencies (Zhang et al., 2018). The HPDV (DFH and XYH) had much lower PM EFs values of 0.72 and $0.16 \mathrm{~g}$ ( $\mathrm{kg}$ fuel) $)^{-1}$, which might be caused by the well-maintained engines and high quality of the fuels used (Zhang et al., 2016). And the HFOV had medium PM emission factors of 3.19-7.48 $\mathrm{g}$ (kg fuel) $)^{-1}$, which was generally similar to the levels of cargo and passenger ships (Endresen et al., 2003; Moldanova et al., 2009).

Carbonaceous matters of OC and EC were the most abundant component in PM, accounting for almost half for HFOV and HPDV, and more than half for LPDF. The detailed mass fractions of (OC + EC)/PM were between $11.9 \%$ and $91.6 \%$, with $2.11 \%-47.9 \%$ of OC and $2.28 \%-87.5 \%$ of EC. OC/EC ratio varied between 0.03 and 21.0. OC was clearly higher than EC in PM for HFOV and other low quality fuel vessels, which was similar to previous study about HFO vessel (Sippula et al., 2014). Water-soluble ions including $\mathrm{SO}_{4}{ }^{2-}, \mathrm{NO}-{ }_{3}^{-}, \mathrm{NH}_{4}{ }^{+}, \mathrm{Cl}^{-}$ and $\mathrm{Na}^{+}$accounted for $1.07 \%-26.9 \%$ of PM for all the test vessels. Much higher proportions of water-soluble ions were accounted for HFOV than HPDV and LPDF, which might be caused by the relative higher sulfur content in fuels that generated more $\mathrm{SO}_{2}$ and higher combustion temperatures in engine cylinders that produced more $\mathrm{NO}_{\mathrm{x}}$. Metal elements such as $\mathrm{Na}, \mathrm{Mg}, \mathrm{K}, \mathrm{Ca}, \mathrm{Fe}, \mathrm{Zn}, \mathrm{Cu}, \mathrm{Mn}, \mathrm{V}$ and $\mathrm{Ni}$ only accounted for very small sections from $0.06 \%$ to $5.36 \%$, also showed higher proportions for HFOV that caused by the relative higher contents of heavy metals in fuels used for HFO vessels. More than half of the components can be identified for most of the vessels, with the remainder inferred as materials such as ash and hydrate materials.

Organic matters (OM) in this study were calculated by using OC $\times 1.2$, which could account for $2.53 \%-57.5 \%$ of the PM mass. Of these, sum of the analyzed organic matters, including 16 priority PAHs, 5 methyl substituted PAHs, and 29 n-alkanes are shown in Fig. 1, accounting for $0.14 \%-23.3 \%$ of PM for all the test vessels. The analyzed organic matters for different vessels showed significant variations. Both HPDV and LPDF showed much higher n-alkanes proportions than HFOV, which might be caused by the fuel types that diesel fuels contain more n-alkanes but less PAHs. N-alkanes were the highest content species for all of the vessels, whose sums made up percentages of $0.11 \%-21.3 \%$ in PM. Though the 16 priority PAHs only accounted for very small proportions of $0.005 \%-0.13 \%$, they played non-ignorable roles in health influence aspect.

\subsection{Emission factors of PAHs and alkanes}

Fuel-based average EFs for PAHs and n-alkanes in PM in this study are shown in Table 1. EFs for $\Sigma 16 \mathrm{PAHs}$ of each vessel ranged between 0.095 and $5.80 \mathrm{mg}$ (kg fuel) $)^{-1}$, $\Sigma$ PAHs ranged between 0.095 and $8.68 \mathrm{mg}$ (kg fuel) ${ }^{-1}$, and EFs for $\Sigma$ n-Alkanes of each vessel ranged between 5.22 and $1589 \mathrm{mg}$ (kg fuel) ${ }^{-1}$ in this study. Both EFs for PAHs and $n$-alkanes varied significantly with the type of the vessels, which were thought to be influenced by the integrated factors of engine parameters, ship tonnage, fuel type and composition (Russell et al., 2000). Fishing boats and the training ship (YK) had relatively higher EFs for PAHs than the light diesel vessels, which had very low values ranged from 95.3 to $477 \mu \mathrm{g}$ (kg fuel) ${ }^{-1}$. Because incomplete combustion of fuels was one of the major sources of carbonyls compounds (Agrawal et al., 2010; Carlier et al., 1986), smaller vessels such as
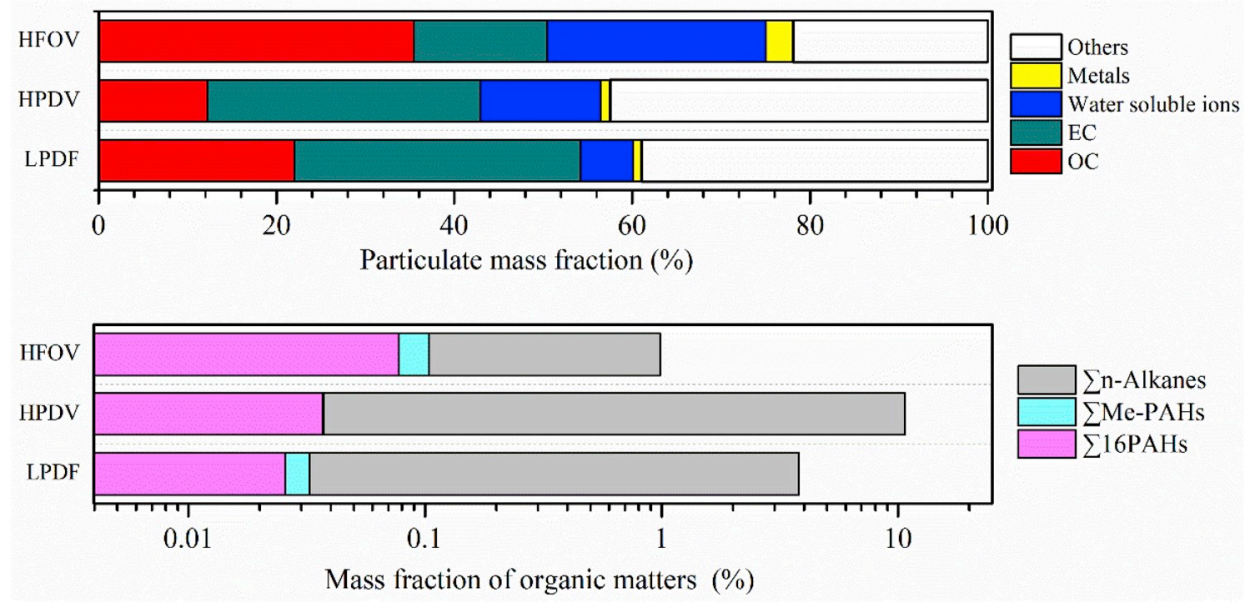

Fig. 1. Chemical composition of PM and the analyzed organic matters (\%). 
Table 1

Emission factors of PAHs and n-alkanes in $\mathrm{PM}\left(\mu \mathrm{g}(\mathrm{kg} \text { fuel })^{-1}\right)$.

\begin{tabular}{|c|c|c|c|c|c|c|c|c|c|c|c|c|c|c|c|}
\hline & GB1 & GB2 & $\mathrm{AB} 1$ & $\mathrm{AB} 2$ & TB1 & TB2 & TB3 & TB4 & TB6 & TB7 & TB8 & $\mathrm{HH}$ & DFH & $\mathrm{XYH}$ & YK \\
\hline Nap & 21.5 & 13.5 & 16.2 & 21.3 & 89.6 & 68.6 & 72.9 & 42.3 & 17.2 & 7.17 & 155 & 0.06 & - & - & 7.14 \\
\hline Acy & - & 17.3 & 3.82 & 10.3 & 95.9 & 74.3 & 18.9 & 17.0 & 5.07 & 10.5 & 185 & 0.51 & - & - & 3.76 \\
\hline Ace & 8.54 & 6.31 & 17.9 & 5.43 & 27.5 & 29.4 & 78.8 & 48.2 & 4.18 & 6.11 & 255 & 4.67 & 2.16 & - & 21.2 \\
\hline Flu & 24.2 & 16.3 & 28.7 & 15.1 & 2.56 & 25.6 & 62.7 & 107 & 7.22 & 21.1 & 724 & 60.7 & 0.10 & 0.15 & 26.2 \\
\hline Phe & 41.6 & 135 & 1777 & 438 & 34.9 & 583 & 205 & 631 & 73.9 & 78.9 & 1755 & 107 & 11.7 & 17.1 & 438 \\
\hline Ant & 186 & 14.0 & 87.4 & 20.2 & 1.17 & 142 & 18.7 & 62.5 & 6.88 & 21.9 & 201 & 0.26 & 0.84 & 0.10 & 159 \\
\hline Flua & 271 & 91 & 793 & 398 & 130 & 742 & 455 & 1129 & 74.8 & 113 & 692 & 83.2 & 60.1 & 10.7 & 847 \\
\hline Pyr & 380 & 200 & 1770 & 782 & 262 & 1641 & 1022 & 1394 & 111 & 198 & 862 & 61.3 & 115 & 44.6 & 1323 \\
\hline $\mathrm{BaA}$ & 1117 & 28.5 & 276 & 50.8 & 25.5 & 18.6 & 302 & 107 & 43.4 & 136 & 174 & 9.82 & 45.6 & 0.63 & 388 \\
\hline Chr & 9.40 & 129 & 925 & 163 & 44.5 & 95.8 & 808 & 477 & 195 & 430 & 622 & 43.8 & 57.7 & 4.49 & 729 \\
\hline $\mathrm{BbF}$ & 402 & 17.8 & 28.3 & 63.0 & 21.6 & 39.1 & 170 & 57.8 & 33.1 & 47.1 & 92.1 & 19.4 & 1.42 & 1.45 & 114 \\
\hline $\mathrm{BkF}$ & 91.7 & 5.19 & 2.52 & 23.0 & 15.0 & 9.97 & 47.7 & 14.6 & 8.19 & 9.64 & 28.4 & 25.4 & 2.27 & 1.14 & 25.4 \\
\hline $\mathrm{BaP}$ & 28.3 & 3.20 & 3.44 & 26.9 & 9.63 & 17.6 & 50.2 & 3.68 & 29.9 & 9.99 & 22.0 & 17.0 & 0.14 & 0.04 & 29.9 \\
\hline IcdP & 3.74 & 6.79 & 11.6 & 43.1 & 12.5 & 9.16 & 36.6 & 2.11 & 5.67 & 2.47 & 10.3 & 13.4 & 12.9 & 4.07 & 13.8 \\
\hline DahA & 48.2 & 2.61 & - & 7.51 & 19.0 & 14.4 & 16.2 & 0.99 & 5.99 & 4.71 & 12.1 & 11.8 & 20.8 & 4.24 & 16.9 \\
\hline BghiP & 47.0 & 7.12 & 9.31 & 70.5 & 3.12 & 1.12 & 66.9 & 4.34 & 7.26 & 4.58 & 14.3 & 17.8 & 13.5 & 6.03 & 24.6 \\
\hline$\Sigma 16$ PAHs & 2681 & 693 & 5751 & 2139 & 795 & 3512 & 3431 & 4098 & 629 & 1101 & 5803 & 476 & 345 & 94.7 & 4168 \\
\hline 1-MeN & 25.5 & 181 & 126 & 294 & 36.5 & 34.1 & 401 & 430 & 138 & 88.1 & 2286 & - & - & 0.03 & 65.2 \\
\hline 2-MeN & 317 & 3.63 & 0.43 & 3.60 & 32.6 & 29.2 & 9.10 & 12.1 & 1.85 & 39.0 & 75.7 & - & - & & 2.58 \\
\hline 2,6-DiN & 10.6 & 10.1 & 27.9 & 18.5 & 24.5 & 30.7 & 21.3 & 27.7 & 6.29 & 20.3 & 136 & - & - & & 10.2 \\
\hline 9-MeA & 97.3 & - & 275 & - & 23.9 & 168 & 9.62 & 11.4 & - & 5.83 & 12.1 & 0.19 & 2.38 & 0.05 & 43.4 \\
\hline MeFlua & 23.3 & 130 & 1718 & 129 & 23.2 & 150 & 627 & 804 & 143 & 95.9 & 363 & 1.11 & 3.89 & 0.52 & 1028 \\
\hline$\Sigma$ MPAHs & 474 & 325 & 2148 & 446 & 141 & 412 & 1068 & 1285 & 290 & 249 & 2873 & 1.29 & 6.27 & 0.60 & 1150 \\
\hline$\Sigma$ PAHs & 3155 & 1018 & 7899 & 2585 & 936 & 3924 & 4499 & 5383 & 919 & 1350 & 8676 & 477 & 351 & 95.3 & 5318 \\
\hline $\mathrm{C} 12$ & 7.96 & 17.6 & - & 8.69 & - & - & 96.8 & - & - & 25.5 & 448 & - & - & - & - \\
\hline $\mathrm{C} 13$ & 4.49 & - & - & 1.27 & - & 0.53 & 70.2 & 21.6 & - & - & 19.4 & - & - & - & - \\
\hline C14 & 2.88 & 23.0 & - & 16.7 & 47.9 & 197 & 328 & 4.27 & 0.54 & - & 196 & - & - & - & - \\
\hline C15 & 5.54 & 94.3 & - & 62.6 & 225 & 1630 & 3621 & 94.4 & 26.9 & 0.95 & 1011 & - & - & 216 & - \\
\hline C16 & 21.4 & 432 & 8616 & 615 & 1203 & 2994 & 6784 & 547 & 228 & 46.0 & 2861 & - & 1615 & 922 & 164 \\
\hline $\mathrm{C} 17$ & 296 & 3159 & 113,649 & 5334 & 11,699 & 27,395 & 7324 & 1758 & 1933 & 46.4 & 3524 & 23.9 & 10,343 & 1564 & 2250 \\
\hline C18 & 1753 & 1722 & 26,979 & 4855 & 25,035 & 27,749 & 5224 & 1041 & 629 & 114 & 913 & 434 & 17,388 & 1927 & 3955 \\
\hline C19 & 947 & 2484 & 116,186 & 9315 & 37,482 & 36,207 & 9865 & 2668 & 1024 & 1.16 & 881 & 2055 & 22,853 & 2332 & 4955 \\
\hline $\mathrm{C} 20$ & 6187 & 4260 & 102,098 & 12,646 & 32,616 & 39,347 & 10,725 & 5646 & 2496 & 418 & 1507 & 2636 & 22,814 & 2268 & 6490 \\
\hline $\mathrm{C} 21$ & 20,131 & 5076 & 86,400 & 13,547 & 10,530 & 30,231 & 8777 & 6938 & 3690 & 463 & 1801 & 3742 & 31,966 & 2235 & 7142 \\
\hline $\mathrm{C} 22$ & 28,103 & 4879 & 137,520 & 10,668 & 20,668 & 445,844 & 15,933 & 7475 & 3774 & 706 & 3574 & 1637 & 18,448 & 846 & 9150 \\
\hline $\mathrm{C} 23$ & 26,143 & 4436 & 106,555 & 8681 & 15,662 & 402,072 & 10,313 & 6234 & 3356 & 646 & 2663 & 1598 & 15,903 & 604 & 8174 \\
\hline $\mathrm{C} 24$ & 18,338 & 3545 & 67,057 & 6450 & 9812 & 250,573 & 6421 & 4484 & 2419 & 520 & 1843 & 1296 & 10,901 & 380 & 6607 \\
\hline $\mathrm{C} 25$ & 10,915 & 2483 & 39,255 & 4317 & 9762 & 252,197 & 3561 & 2389 & 1692 & 466 & 1203 & 1285 & 10,841 & 378 & 5440 \\
\hline $\mathrm{C} 26$ & 6068 & 1563 & 13,591 & 2897 & 2168 & 701,54 & 2692 & 2841 & 1263 & 414 & 642 & 444 & 2760 & 112 & 3725 \\
\hline $\mathrm{C} 27$ & 3628 & 590 & 589 & 1491 & 945 & 1394 & 3414 & 1474 & 628 & 295 & 388 & 283 & 1181 & 80.7 & 2729 \\
\hline $\mathrm{C} 28$ & 1662 & 511 & - & 855 & 328 & 496 & 1775 & 1029 & 465 & 383 & 1445 & 158 & 427 & 45.4 & 2068 \\
\hline $\mathrm{C} 29$ & 1300 & 159 & - & 330 & 157 & 193 & 573 & 718 & 379 & 150 & 198 & 62.5 & 138 & 25.9 & 1437 \\
\hline C30 & 615 & 178 & 190 & 163 & 85.1 & 83.9 & 1756 & 256 & 403 & 209 & 232 & 39.8 & 53.3 & 13.9 & 2018 \\
\hline C31 & 360 & 99.4 & 209 & 68.0 & 61.9 & 47.3 & 1421 & 211 & 273 & 140 & 208 & 33.2 & 43.5 & 19.8 & 1122 \\
\hline C32 & 373 & 27.3 & 48.4 & 35.8 & 54.0 & 40.5 & 319 & 183 & 190 & 96.2 & 129 & 15.4 & 34.6 & 7.65 & 1065 \\
\hline C33 & 178 & 21.8 & 64.9 & 14.8 & 42.0 & 34.2 & 451 & 76.2 & 83.5 & 38.3 & 62.1 & 3.45 & 4.65 & 0.01 & 382 \\
\hline C34 & 60.0 & 68.5 & 48.2 & 13.8 & 65.8 & 38.6 & 87.5 & 23.4 & 54.4 & 15.9 & 57.5 & 2.52 & 1.13 & 0.20 & 324 \\
\hline C35 & 37.4 & 9.72 & 36.3 & 3.94 & 51.0 & 38.8 & 149 & 16.4 & 30.5 & 17.2 & 58.1 & 2.67 & 3.08 & 0.57 & 310 \\
\hline C36 & 66.2 & 8.51 & 81.3 & 9.52 & 54.2 & 40.6 & 61.5 & 30.9 & 24.7 & 4.62 & 124 & 1.17 & & 0.04 & 72.4 \\
\hline C37 & 41.4 & 18.9 & 70.0 & 5.20 & 43.8 & 31.0 & 88.9 & 8.85 & 9.52 & 0.06 & 74.9 & 0.66 & 0.52 & 0.03 & 123 \\
\hline C38 & 33.4 & 6.24 & 40.3 & - & 88.8 & 65.4 & 102.4 & - & 7.66 & 0.80 & 53.9 & 0.77 & - & - & 35.5 \\
\hline C39 & 17.3 & 4.89 & 47.7 & 1.49 & 100 & 76.1 & 96.0 & 0.85 & 5.14 & - & 30.9 & 1.18 & - & - & 17.2 \\
\hline $\mathrm{C} 40$ & 2.83 & - & 74.4 & - & 87.5 & 68.3 & 146 & 0.17 & - & - & 67.7 & 1.39 & - & - & - \\
\hline$\Sigma$ n-Alkanes & 127,299 & 35,878 & 819,405 & 82,406 & 179,076 & 1589,238 & 102,175 & 46,170 & 25,086 & 5217 & 26,213 & 15,757 & 167,718 & 13,978 & 69,754 \\
\hline
\end{tabular}

fishing boats in this study had more incomplete combustion process (Diesch et al., 2013; Zhang et al., 2018), which might lead to the increase of PAHs emissions. Besides, it is confirmed that low-sulfur fuel would considerably reduce emissions of PAHs with respect to the use of high sulfur content fuel (Cooper and Gustafsson, 2004; Donateo et al., 2014; Endresen et al., 2003). However, there was not a perfect linear dependency of sulfur and PAHs emission factors in this study, which might be caused by the different fuel qualities that not only decided by the sulfur contents. As for n-alkanes, fishing boats with lower power engines had relatively higher EFs, and HFO fuel vessels had relatively lower EFs in this study. There was a correlation coefficient of 0.80 between the sulfur content of fuels and the ratios of $\Sigma 16$ PAHs to $\Sigma \mathrm{n}-$ alkanes in this study, which means more PAHs than n-alkanes emitted from HFO fuel vessels compared with DF vessels. This was inferred as higher fraction content of polycyclic aromatic compounds in HFO fuel than DF, HFO fuel vessels usually emit substantially higher amounts of various PAHs, O-PAHs and Nitro-PAHs than n-alkanes compared with DF vessels (Sippula et al., 2014). Besides, methylic-PAHs in this study had obviously lower EFs of clean diesel fuel than high-sulfur content fuels, which was also confirmed by previous study (Sippula et al., 2014).

In order to give comparison of ship emissions with other studies, emission factors for the total 15 priority control PAHs (except for Nap, which was influenced significantly by temperature because of its high volatility), total n-alkanes (from Dodecane to Tetracontane), and their proportions in this study and previous studies are given in Figure A1 and Figure A2.

The results showed that emission factors for the $\Sigma_{15} \mathrm{PAHs}$ in this study were in the range of the results from previous studies. HFO ships (from references of R1 (Agrawal et al., 2010), R2 (Murphy et al., 2009), 
R3 (Agrawal et al., 2008), R5-10 and R5-11 (Cooper, 2003)) and fishing boats had higher $\Sigma_{15} \mathrm{PAHs}$ emission factors compared with diesel fuel ships, which inferred that HFO fuel ships and fishing boats had more potential health effects, especially in offshore areas. The dominant PAH species were Flu, Phe, Flua and Pyr, but with significant differences in proportion of different ships, which might be caused by the combustion temperature in the cylinder.

As for n-alkanes, diesel fuel vessels showed higher emission factors than HFO vessels, especially for fishing boats with diesel fuel in this study. Because n-alkanes emitted from engines were typically related to the fuel types, diesel fuel generally contain more aliphatic compounds than HFO (Sippula et al., 2014). High EFs for n-alkanes of diesel engine vessels implied a large amount of incomplete combustion fuel might be emitted along with the exhaust, which had been proved in this study that diesel fuel vessels such as fishing boats had relatively lower combustion efficiencies compared with HFO vessels.

\subsection{Emission profiles of organic compounds}

In order to give PAHs profiles in PM emitted from ships, as the same as before, the test vessels in this study were also divided into three categories of LPDF, HPDV, and HFOV. As seen in Fig. 2, the major compounds were Pyr, Flua, Phe, and Chr for all the test vessels in this study, which had the similar result to previous studies about PAHs emitted from harbor ships (Cooper, 2003) and tested in harbor area (Donateo et al., 2014). Both low and high molecular weight PAHs only accounted for very small proportions in this study. As shown in Figure A3, three- and four-ring PAHs of medium molecular weight were the dominant species that could account for $67 \%-98 \%$ of the total 16 PAHs mass. Among the three categories, the LPDF and the HFOV showed similar PAH distributions that had relatively higher proportions in low molecular weight PAHs but lower proportions in high molecular weight PAHs compared with HPDV. PAHs emitted from other sources showed significant differences, such as high composition in Nap, Pyr, Phe for heavy-duty diesel vehicles (Shah et al., 2005); high composition in Pyr, BghiP, Flua and Phe for road dust (Pengchai et al., 2004); high composition in high molecular weight PAHs of DahA, BghiP, IcdP and medium molecular weight PAHs of Flua, and Pyr for biomass combustion (Oanh et al., 2005); high composition in high molecular weight PAHs of BbF, BghiP, IcdP and also Chr, Phe for coal combustion (Chen et al., 2004, 2005); high composition in low molecular weight PAHs for gasoline-powered motor vehicles (Schauer et al., 2002). Detailed PAH profiles of vessels might provide strong evidence to identify ship emissions from other sources in source apportionment, which could give results that are more precise.

The $n$-alkane profiles for the three types of vessels in this study are shown in Fig. 2. N-Docosane (C22) was the highest composition for both LPDF and HFO vessel, but n-heneicosane (C21) was the highest composition for HPDV. Diesel fuel vessels had higher proportions in low carbon number n-alkanes $(<21)$, and HFOV had higher proportions in high carbon number n-alkanes $(>22)$ with a broader distribution of alkanes, which was in accordance with previous study (Sippula et al., 2014). Because n-alkanes emitted from engines were typically related to the fuel types, high quality light diesel with more low-carbon chains used for the diesel vessels could responsible for the lower carbon number n-alkanes, and vice versa. All the test vessels had very small proportions of n-alkanes with both low carbon number $(<15)$ and high carbon number ( $>33$ ), which only accounted for less than $3 \%$ of the total $\mathrm{n}$-alkanes. $\mathrm{N}$-alkanes emitted from different emission sources always showed different profile characteristics, which could be used for source apportionment. Motor vehicles, biomass combustion and coal combustion are the most concerned air pollution sources in China. The results showed that $\mathrm{n}$-alkanes emitted from light-duty vehicles typically had variant maximum carbon numbers from different studies, which could range from C21-C30 (Chellam et al., 2005; Dai et al., 2015; Huang et al., 2016; Perrone et al., 2014), yet typically with C24-C26 as the most possible maximum carbon numbers. N-alkanes emitted from biomass in different studies had very consistent characteristics that $\mathrm{n}$ Nonacosane (C29) was the maximum carbon number and showed obvious odd-carbon advantage (Hays et al., 2005; Vasconcellos et al., 2010; Yan et al., 2008; Zhang et al., 2007). Coal combustion is a large air pollution source in China, especially in winter. The results from previous studies showed that $\mathrm{C} 23$ and $\mathrm{C} 21$ were the $\mathrm{C}_{\max }$ in heating season (Duan et al., 2010; Xie et al., 2009), which could be characteristics of coal combustion. Besides, N-Eicosane (C20) was the highest composition for biodiesel exhaust PM, followed by C19, C21, C18 and C22, others only accounted for very small proportions (Kasumba and Holmen, 2016). The results in this study inferred that combined with detailed profiles of both PAHs and n-alkanes, it will be benefit to give more precise source apportionment results.

\subsection{Diagnostic characteristics of $P A H$ and n-alkanes in $P M$}

$\mathrm{PAH}$ diagnostic ratios have come into common use recently as a tool for the identification and assessment of pollution emission sources, such as diesel and gasoline combustion emission (Ravindra et al., 2008a),
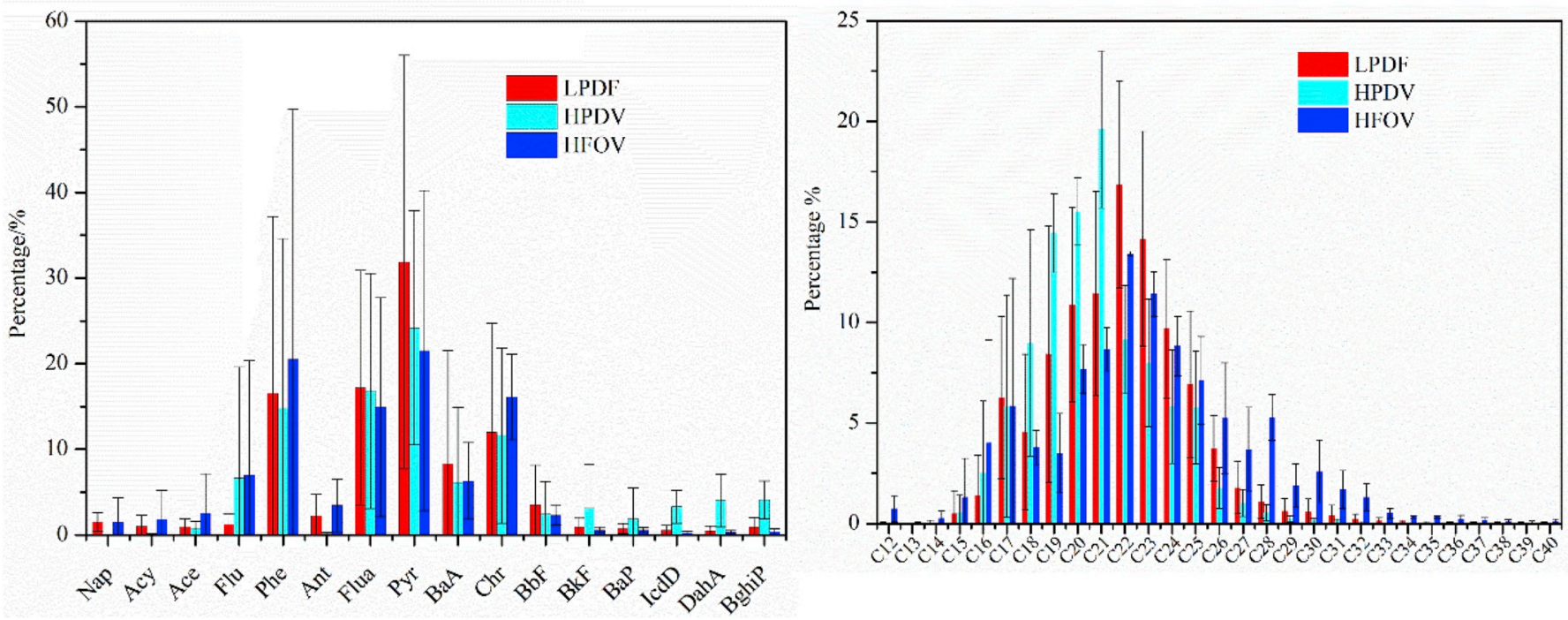

Fig. 2. PAHs and n-alkanes profiles for the test vessels. 
different crude oil processing products and biomass burning processes, including bush, savanna and grass fires (Yunker et al., 2002). Table 2 and Figure A4 list the PAH diagnostic ratio ranges from different sources in previous studies and this study. The results showed that the ratios of Ant/(Ant + Phe), Flua/(Flua + Pyr), Flu/(Flu + Pyr), and IcdP/(IcdP + BghiP) in PM emitted from marine fuel combustion indicated obvious petroleum combustion characteristics compared with previous studies. An Ant/(Ant + Phe) ratio of 0.1 is often applied to distinguish petrogenic $(<0.1)$ from pyrogenic/combustion $(>0.1)$ sources (Pies et al., 2008). The ratios for most fuels in the present study were lower than 0.1 , supporting the petrogenic characteristics. It is generally indicated the petrol emissions when the ratio of Flua/ (Flua + Pyr) is less than 0.5 (De La Torre-Roche et al., 2009). This was well supported by the ratios of Flua/(Flua + Pyr) in this study, ranging between 0.31 and 0.42 . The ratios of Flu/(Flu + Pyr) ranged between 0.02 and 0.08 in this study, corresponding to the conclusion that it indicated the petrol emissions when the ratio is less than 0.5 (Ravindra et al., 2008b). An IcdP/(IcdP + BghiP) ratio of 0.5 is usually recommended as a criterion separating liquid fossil fuel combustion $(<0.5)$ and grass/wood/coal combustion (>0.5) (Yunker et al., 2002). This was also well supported by the ratios calculated in this study, varying narrowly from 0.35 to 0.49 . However, other diagnostic ratios were not so well consistent with previous studies, for example, BaA/ $(\mathrm{BaA}+\mathrm{Chr})$ ratios varied from 0.18 to 0.35 in this study, making it difficult to distinguish from coal combustion with a ratio range of $0.2-0.35$ given by a previous study (Yunker et al., 2002). Ratios of BaP/ BghiP, Phe/Ant, and BaA/Chr are also given in the present study in Table 2, however, these ratios varied significantly among different studies (Cereceda-Balic et al., 2012; Ravindra et al., 2008a; Tobiszewski and Namiesnik, 2012). It meant they should be used carefully in evaluating sources. In fact, simultaneous application of more than one PAH diagnostic ratio might help to reduce the uncertainty in source apportionment calculation.

As for n-alkanes, diagnostic parameters such as ratio of low molecular weight to high molecular weight (LMW/HMW), the average chain length (ACL), the maximum carbon number $\left(\mathrm{C}_{\max }\right)$, and the carbon preference index (CPI) in this study and previous studies from different sources are shown in Table 3. Ratio of $\mathrm{W}\left(\mathrm{nC} 23^{-}\right) / \mathrm{W}\left(\mathrm{nC}^{2} 3^{+}\right)$was discussed in this study to represent the characteristic of LMW/HMW as it could indicate different sources, especially for anthropogenic source and biogenic source. It showed that almost all the $\mathrm{W}\left(\mathrm{nC} 23^{-}\right) / \mathrm{W}\left(\mathrm{nC}^{2} 3^{+}\right)$ ratios of anthropogenic sources had values higher than 0.5 , and very low values for biogenic sources of $0.04-0.24 . \mathrm{C}_{\max }$ is defined as the carbon number of the alkane that has the highest concentration in the n-alkanes. As the same as $\mathrm{W}\left(\mathrm{nC}^{-}\right) / \mathrm{W}\left(\mathrm{nC}^{-} 3^{+}\right)$ratio, $\mathrm{C}_{\max }$ also had very noticeable characteristic for different sources. All the biogenic sources from previous studies had the same $\mathrm{C}_{\max }$ of 29 , as for anthropogenic sources, all the $C_{\max }$ values were lower than 25 , which was corresponding to previous study that defined 25 as a threshold (Bin Abas and Simoneit, 1996). And in this study, all the n-alkanes in PM emitted from the test vessels had $C_{\max }$ values ranged from 19 to 21 , a little smaller than motor vehicles (Chellam et al., 2005; Dai et al., 2015). Besides, ACL also can be used to distinguish different sources', for example, all the biogenic sources had ACL values larger than 27.8 in previous studies (Hays et al., 2005; Vasconcellos et al., 2010; Zhang et al., 2007), however, all anthropogenic sources had ACL values

Table 2

Diagnostic ratios of typical PAHs used in source apportionment.

\begin{tabular}{|c|c|c|c|}
\hline $\mathrm{PAH}$ ratio & Value range & Source & Reference \\
\hline \multirow[t]{3}{*}{ Ant/(Ant + Phe) } & $0.04-0.20^{\mathrm{a}}$ & Marine fuel combustion & This study \\
\hline & $<0.1$ & Petroleum & Pies et al. (2008) \\
\hline & $>0.1$ & Combustion & \\
\hline \multirow[t]{4}{*}{ Flua/(Flua + Pyr) } & $0.31-0.42^{\mathrm{a}}$ & Marine fuel combustion & This study \\
\hline & $<0.4$ & Petrogenic & De La Torre-Roche et al. (2009) \\
\hline & $<0.5$ & Petrol emissions & \\
\hline & $>0.5$ & Wood combustion & \\
\hline \multirow[t]{5}{*}{$\mathrm{BaA} /(\mathrm{BaA}+\mathrm{Chr})$} & $0.18-0.35^{\mathrm{a}}$ & Marine fuel combustion & This study \\
\hline & $0.2-0.35$ & Coal combustion & Akyuz and Cabuk. (2010) \\
\hline & $>0.35$ & Vehicular emission & \\
\hline & $<0.2$ & Petroleum & Yunker et al. (2002) \\
\hline & $>0.35$ & Combustion & \\
\hline \multirow[t]{4}{*}{ IcdP/(IcdP + BghiP $)$} & $0.35-0.49^{\mathrm{a}}$ & Marine fuel combustion & This study \\
\hline & $<0.2$ & Petroleum & Yunker et al. (2002) \\
\hline & $0.2-0.5$ & Liquid fossil fuel combustion & \\
\hline & $>0.5$ & Grass, wood/coal combustion & \\
\hline \multirow[t]{3}{*}{ BaP/BghiP } & $<0.01^{\mathrm{a}}$ & Marine fuel combustion & This study \\
\hline & $<0.6$ & Non-traffic emissions & Katsoyiannis et al. (2007) \\
\hline & $>0.6$ & Traffic emissions & \\
\hline \multirow[t]{5}{*}{ Flu/(Flu + Pyr) } & $0.02-0.08^{\mathrm{a}}$ & Marine fuel combustion & This study \\
\hline & $<0.5$ & Petrol emissions & Ravindra et al. (2008b) \\
\hline & $>0.5$ & Diesel emissions & \\
\hline & $0.4-0.5$ & Fuel combustion & Katsoyiannis et al. (2007) \\
\hline & $>0.5$ & Grass, wood/coal combustion & \\
\hline \multirow[t]{7}{*}{ Phe/Ant } & $4.12-21.7^{\mathrm{a}}$ & Marine fuel combustion & This study \\
\hline & 2.7 & Vehicles & Simcik et al. (1999) \\
\hline & 8 & Street dust & \\
\hline & $3.4-8$ & Gasoline exhaust & \\
\hline & 3 & Firewood fire/coal & \\
\hline & $7.6-8.8$ & Diesel & \\
\hline & 0.79 & Coke oven & \\
\hline \multirow[t]{7}{*}{$\mathrm{BaA} / \mathrm{Chr}$} & $0.22-0.53^{\mathrm{a}}$ & Marine fuel combustion & This study \\
\hline & 0.63 & Vehicles & Simcik et al. (1999) \\
\hline & $0.28-1.2$ & Gasoline exhaust & \\
\hline & 0.93 & Firewood fire & \\
\hline & $1.0-1.2$ & Coal & \\
\hline & $0.17-0.36$ & Diesel & \\
\hline & 0.70 & Coke oven & \\
\hline
\end{tabular}

a The value ranges given in this study were between 25 th and 75 th percentile of the total test values. 
smaller than 26.36 in this study and previous studies shown in Table 3. Therefore, ACL value of 27 could consider being a divide point for anthropogenic source and biogenic source. Moreover, the CPI is a common indicator to distinguish the contribution of biogenic organic matter and anthropogenic sources to organic aerosol (Simoneit, 1989). The alkane CPI is defined as the sum of the concentrations of odd carbon number alkanes divided by the sum of the concentrations of even carbon number alkanes. A CPI near unity is expected for anthropogenic sources, and larger than one is expected for biogenic sources (Choiseul et al., 1998). It was completely obvious in Table 3 that biogenic sources had higher CPI values (1.48-11.53) than anthropogenic sources with values near unity (0.77-1.36).

Diagnostic parameters of $\mathrm{n}$-alkanes in PM could provide very recognizable evidence to distinguish anthropogenic source and biogenic source. Moreover, PAH diagnostic ratios could be used to identify petrogenic source, different fuel combustion, biomass burning, etc. If possible, these two diagnostic methods, along with n-alkanes and PAHs profiles, should be taken into consideration together, which will be preferred in source apportionment calculation.

\subsection{Potential toxicity risk assessment of PAHs in PM emitted from vessels}

Widely known parameters, including 2,3,7,8-tetrachlorodibenzodioxin (TCDD)-based toxicity equivalency concentration (TEQ), total carcinogenic PAHs (C-PAHs), and BaP-based equivalency concentration (BaPeq) have been extensively applied to assess PAH risks to humans (Chen et al., 2004; Finardi et al., 2017; Li et al., 2016b, 2018; Liu et al., 2009; Nguyen-Duy and Chang, 2017). The calculated results of potential toxicity risk of PAHs in this study are shown in Table 4. It showed that the three toxicity risk assessment methods indicated the similar results. Therefore, TEQ was discussed only in this study to assess the potential toxicity risk of PAHs in PM emitted from vessels. The results showed that TEQ varied largely for the test vessels in this study, ranging from 5.192 to $241.1 \mu \mathrm{g}$ (kg fuel) ${ }^{-1}$, with GB1, TB3, and YK having the highest values, and light-diesel engines of DFH and $\mathrm{XYH}$ having the lowest values. The dominant compounds were $\mathrm{BaA}, \mathrm{BbF}$, Bap, and DahA, with four and five-ring PAHs accounting for $73 \%-98 \%$ of the total TEQ (seen in Figure A5). The sulfur content in the fuels had no obvious relationship with the TEQ. This was consistent with the result that PAHs EFs had no positive correlation with sulfur content in the fuels, which might be caused by the same reason that fuel quality of vessels in China might not only evaluated by the sulfur contents.

Comparison of TEQ in PM from different sources are given in Figure A6, including the vessels in this study and previous studies, biomass combustion, coal combustion, and vehicles with different fuels from previous studies. In order to give the most intuitive comparison, all the TEQ values were unified into $\mu \mathrm{g}(\mathrm{g} \mathrm{PM})^{-1}$ in this study. The results showed that the TEQ from marine vessels in this study had a medium level, ranging from 1.76 to $38.8 \mu \mathrm{g}(\mathrm{g} \mathrm{PM})^{-1}$, a little lower than previous studies of HFO vessel exhausts, almost the same level with diesel vehicles (Borras et al., 2009; Riddle et al., 2007; Shah et al., 2005), but lower than gasoline and liquefied petroleum gas vehicles (Yang et al., 2007). Besides, residential coal combustion showed much higher TEQ values (Chen et al., 2005; Liu et al., 2009), which was three to five orders of magnitude higher than that of diesel engines. However, open

Table 3

Characteristics of n-alkanes from different sources in this study and previous studies.

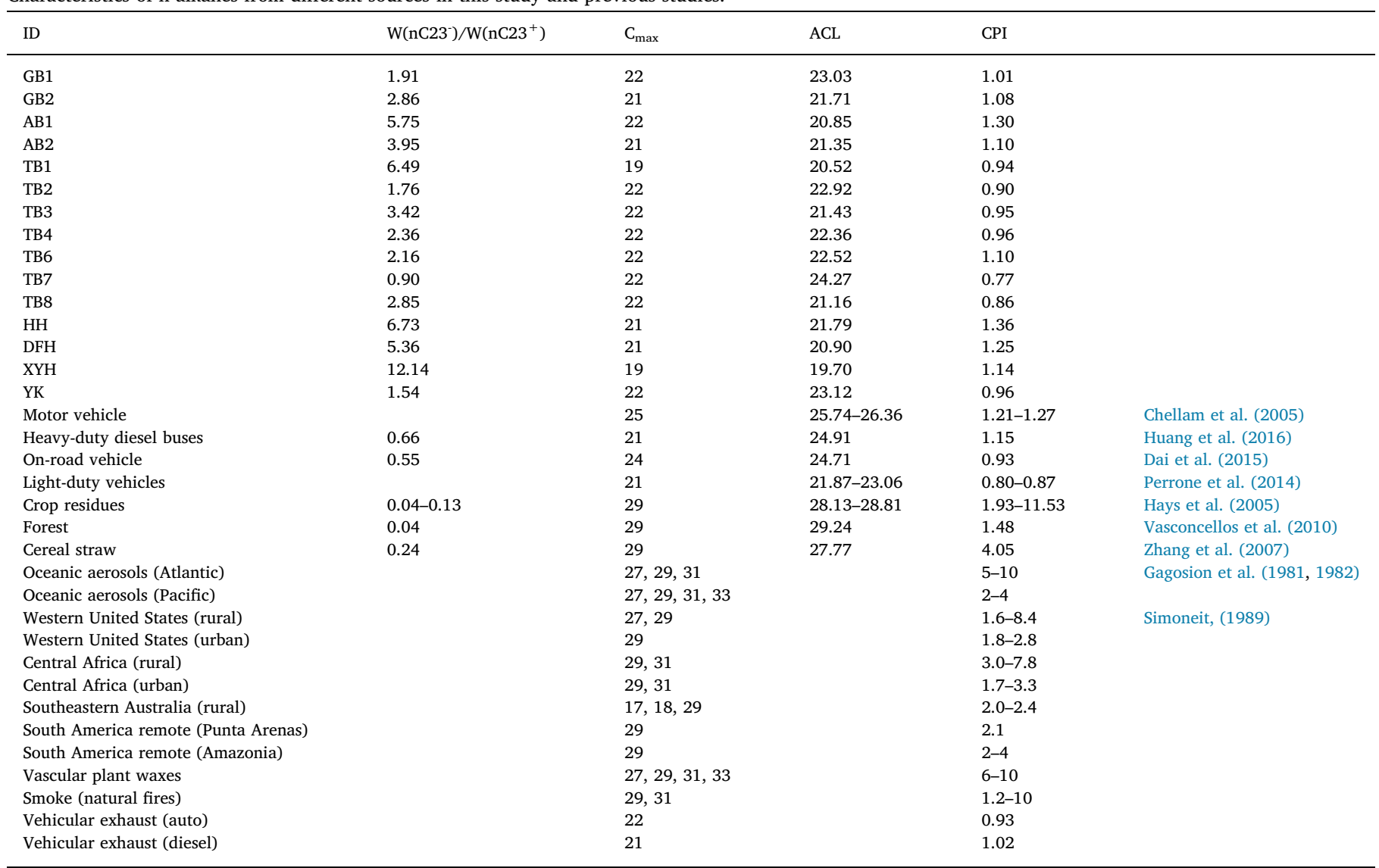

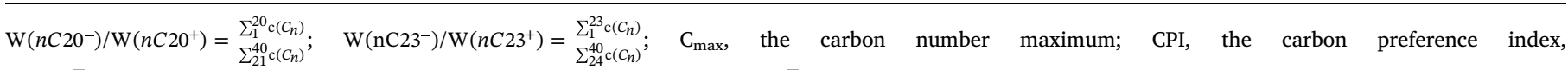
$\mathrm{CPI}=\frac{\sum \text { concentrations of odd carbon number homologs }}{\sum \text { concentrations of even carbon number homologs }}$; ACL, the average chain length, $\mathrm{ACL}=\frac{\sum\left\{n \times \mathrm{c}\left(C_{n}\right)\right\}}{\sum c\left(C_{n}\right)}, \mathrm{c}\left(C_{n}\right)$, concentration of $\mathrm{n}$-alkane with carbon number of $\mathrm{n}$. 
Table 4

Toxic equivalents of the 16 priority control PAHs $\left(\mu g(\mathrm{~kg} \text { fuel })^{-1}\right)$.

\begin{tabular}{|c|c|c|c|c|c|c|c|c|c|c|c|c|c|c|c|}
\hline & GB1 & GB2 & $\mathrm{AB} 1$ & $\mathrm{AB} 2$ & TB1 & TB2 & TB3 & TB4 & TB6 & TB7 & TB8 & $\mathrm{HH}$ & DFH & XYH & YK \\
\hline Nap & 0.021 & 0.014 & 0.016 & 0.021 & 0.090 & 0.069 & 0.073 & 0.042 & 0.017 & 0.007 & 0.155 & 0.000 & 0.000 & 0.000 & 0.007 \\
\hline Acy & 0.000 & 0.017 & 0.004 & 0.010 & 0.096 & 0.074 & 0.019 & 0.017 & 0.005 & 0.010 & 0.185 & 0.001 & 0.000 & 0.000 & 0.004 \\
\hline Ace & 0.009 & 0.006 & 0.018 & 0.005 & 0.028 & 0.029 & 0.079 & 0.048 & 0.004 & 0.006 & 0.255 & 0.005 & 0.002 & 0.000 & 0.021 \\
\hline Flu & 0.024 & 0.016 & 0.029 & 0.015 & 0.003 & 0.026 & 0.063 & 0.107 & 0.007 & 0.021 & 0.724 & 0.061 & 0.000 & 0.000 & 0.026 \\
\hline Phe & 0.042 & 0.135 & 1.777 & 0.438 & 0.035 & 0.583 & 0.205 & 0.631 & 0.074 & 0.079 & 1.755 & 0.107 & 0.012 & 0.017 & 0.438 \\
\hline Ant & 1.862 & 0.140 & 0.874 & 0.202 & 0.012 & 1.416 & 0.187 & 0.625 & 0.069 & 0.219 & 2.008 & 0.003 & 0.008 & 0.001 & 1.593 \\
\hline Flua & 0.271 & 0.091 & 0.793 & 0.398 & 0.130 & 0.742 & 0.455 & 1.129 & 0.075 & 0.113 & 0.692 & 0.083 & 0.060 & 0.011 & 0.847 \\
\hline Pyr & 0.380 & 0.200 & 1.771 & 0.782 & 0.262 & 1.641 & 1.022 & 1.394 & 0.111 & 0.198 & 0.862 & 0.061 & 0.115 & 0.045 & 1.323 \\
\hline $\mathrm{BaA}$ & 112 & 2.849 & 27.61 & 5.084 & 2.550 & 1.860 & 30.20 & 10.72 & 4.335 & 13.64 & 17.37 & 0.982 & 4.557 & 0.063 & 38.79 \\
\hline Chr & 0.094 & 1.288 & 9.252 & 1.634 & 0.445 & 0.958 & 8.080 & 4.767 & 1.950 & 4.296 & 6.217 & 0.438 & 0.578 & 0.045 & 7.295 \\
\hline BbF & 40.20 & 1.775 & 2.833 & 6.300 & 2.162 & 3.910 & 17.05 & 5.777 & 3.311 & 4.714 & 9.214 & 1.938 & 0.141 & 0.145 & 11.44 \\
\hline BkF & 9.175 & 0.519 & 0.252 & 2.296 & 1.501 & 0.997 & 4.707 & 1.406 & 0.819 & 0.964 & 2.837 & 2.541 & 0.227 & 0.114 & 2.541 \\
\hline BaP & 28.26 & 3.198 & 3.439 & 26.90 & 9.634 & 17.62 & 50.25 & 3.680 & 29.89 & 9.991 & 22.03 & 17.022 & 0.137 & 0.044 & 29.88 \\
\hline IcdP & 0.374 & 0.679 & 1.161 & 4.309 & 1.250 & 0.916 & 3.664 & 0.211 & 0.567 & 0.247 & 1.029 & 1.336 & 1.285 & 0.407 & 1.382 \\
\hline DahA & 48.24 & 2.607 & 0.000 & 7.509 & 19.03 & 14.42 & 16.16 & 0.988 & 5.994 & 4.712 & 12.11 & 11.80 & 20.84 & 4.241 & 16.95 \\
\hline BghiP & 0.470 & 0.071 & 0.093 & 0.705 & 0.031 & 0.011 & 0.669 & 0.043 & 0.073 & 0.046 & 0.143 & 0.178 & 0.135 & 0.060 & 0.246 \\
\hline$\Sigma T E Q$ & 241.1 & 13.61 & 49.92 & 56.61 & 37.26 & 45.27 & 132.9 & 31.58 & 47.30 & 39.27 & 77.59 & 36.56 & 28.10 & 5.192 & 112.8 \\
\hline C-PAHs ${ }^{\mathrm{a}}$ & 1700 & 192.9 & 1247 & 377.8 & 147.8 & 204.7 & 1430 & 662.5 & 321.2 & 640.0 & 960.4 & 140.6 & 140.8 & 16.05 & 1318 \\
\hline $\mathrm{BaPE}^{\mathrm{b}}$ & 159.1 & 8.621 & 23.09 & 43.92 & 26.14 & 31.56 & 96.22 & 15.90 & 39.43 & 25.17 & 48.98 & 28.90 & 16.66 & 3.133 & 74.20 \\
\hline
\end{tabular}

a C-PAHs, Sum of seven carcinogenic PAHs (marked by bold font) ( $\mu \mathrm{g}$ (kg fuel) ${ }^{-1}$ ).

b The BaP-equivalent carcinogenic power $(\mathrm{BaPE})$ for the total PAHs $\left(\mu \mathrm{g}\left(\mathrm{kg}\right.\right.$ fuel) $\left.{ }^{-1}\right)$ : $\mathrm{BaPE}=\mathrm{BaA} \times 0.06+\mathrm{B}[\mathrm{b}, \mathrm{k}] \mathrm{F} \times 0.07+\mathrm{BaP}+\mathrm{DahA} \times 0.6+\mathrm{IcdP} \times 0.08$ ((Liu et al., 2009)).

fire had the lowest TEQ values (Gullett et al., 2012), a little lower than cookstove with different fuels (Oanh et al., 2005). Biomass TEQ varied largely in previous studies, which might be caused by the different combustion conditions. Although the TEQ from marine vessels were not so high, the health effect still cannot be neglected considering of the high emission factors of PM and the large amount of total PM emitted from vessels, especially in coastal areas (Chen et al., 2017; Zhang et al., 2018). Besides, a large amount of heavy metal elements are always emitted from ship exhausts, which could enhance the healthy influence further.

\section{Conclusions}

(1) Identified organic pollutants including 16 priority PAHs, 5 methyl substituted PAHs, and $29 \mathrm{n}$-alkanes in this study accounted for $0.14 \%-23.3 \%$ of PM for all the test vessels, with significant variations for different vessels. $\mathrm{N}$-alkanes were the highest content species, whose sums made up percentages of $0.11 \%-21.3 \%$. The 16 priority PAHs only accounted for very small proportions of $0.005 \%-0.13 \%$.

(2) Fuel-based average EFs for $\Sigma 16 \mathrm{PAHs}$ and $\Sigma \mathrm{n}$-alkanes of each vessel ranged between 0.095 and $5.80 \mathrm{mg}$ (kg fuel) $)^{-1}, 5.22$ and $1589 \mathrm{mg}$ (kg fuel) $)^{-1}$ in this study, respectively. Fishing boats and the HFO training ship had relatively higher EFs for PAHs compared with light diesel vessels. However, as for n-alkanes, fishing boats with lower power engines and HFO vessels had relatively higher EFs levels compared with other vessels.

(3) Three- and four-ring PAHs of medium molecular weight accounted for $67 \%-98 \%$ of the total 16 PAHs, with Pyr, Flua, Phe, and Chr were the major compounds for all the test vessels in this study. $\mathrm{N}$ alkanes from C15 to C33 accounted for more than 97\% of the total $\mathrm{n}$-alkanes. Both PAHs and n-alkanes profiles in PM emitted from ships showed significant differences compared with other sources. Besides, the ratios of Ant/(Ant + Phe), Flua/(Flua + Pyr), Flu/ (Flu + Pyr), and IcdP/(IcdP + BghiP) in PM in this study indicated obvious petroleum combustion characteristics. Moreover, it was proved that diagnostic characteristics of $\mathrm{W}\left(\mathrm{nC} 23^{-}\right) / \mathrm{W}\left(\mathrm{nC}_{2} 3^{+}\right)$, $\mathrm{C}_{\max }$, ACL, and CPI of n-alkanes in PM also can be used to distinguish ship emissions from other sources. Therefore, if possible, profiles of both PAHs and n-alkanes, along with their diagnostic characteristics should be taken into consideration together, which could provide possible approach to identify ship emissions from other sources in source apportionment.

(4) Potential toxicity risk of PAHs in PM from different emission sources were assessed, the results showed that the TEQ from marine vessels in this study had a medium level compared with other sources. However, the health influence still cannot be ignored due to the large amount of total PM emitted from ships in offshore areas.

This study fills a research gap by providing detailed EFs, profiles and diagnostic characteristics of organic pollutants in PM emitted from various vessels in China. In doing so, this study helps to estimate emission inventories of organic pollutants emitted from vessels and improve the accuracies of ship emission source identification and source apportionment.

\section{Notes}

The authors declare no competing financial interest.

\section{Acknowledgements}

This study was financially supported by the Natural Science Foundation of China (grant numbers 41761134083, 41603090, 91744203, and 41473091), National Research Program for Key Issues in Air Pollution Control (grant numbers DQGG0201), and the Fundamental Research Funds for the Central Universities.

\section{Appendix A. Supplementary data}

Supplementary data to this article can be found online at https:// doi.org/10.1016/j.atmosenv.2018.12.006.

\section{References}

Agrawal, H., Welch, W.A., Henningsen, S., Miller, J.W., Cocker III, D.R., 2010. Emissions from main propulsion engine on container ship at sea. J. Geophys. Res. Atmos. 115. Agrawal, H., Welch, W.A., Miller, J.W., Cocker, D.R., 2008. Emission measurements from a crude oil tanker at sea. Environ. Sci. Technol. 42, 7098-7103.

Akyuz, M., Cabuk, H., 2010. Gas-particle partitioning and seasonal variation of polycyclic aromatic hydrocarbons in the atmosphere of Zonguldak, Turkey. Sci. Total Environ. 408, 5550-5558.

Anderson, M., Salo, K., Hallquist, A.M., Fridell, E., 2015. Characterization of particles 
from a marine engine operating at low loads. Atmos. Environ. 101, 65-71.

Bin Abas, M.R., Simoneit, B.R.T., 1996. Composition of extractable organic matter of air particles from Malaysia: initial study. Atmos. Environ. 30, 2779-2793.

Borras, E., Tortajada-Genaro, L.A., Vazquez, M., Zielinska, B., 2009. Polycyclic aromatic hydrocarbon exhaust emissions from different reformulated diesel fuels and engine operating conditions. Atmos. Environ. 43, 5944-5952.

Bray, E., Evans, E., 1961. Distribution of n-paraffins as a clue to recognition of source beds. GeCoA 22, 2-15.

Carlier, P., Hannachi, H., Mouvier, G., 1986. The chemistry of carbonyl-compounds in the atmosphere - a review. Atmos. Environ. 20, 2079-2099.

Celo, V., Dabek-Zlotorzynska, E., McCurdy, M., 2015. Chemical characterization of exhaust emissions from selected Canadian marine vessels: the case of trace metals and lanthanoids. Environ. Sci. Technol. 49, 5220-5226.

Cereceda-Balic, F., Fadic, X., Llanos, A.L., Maria Dominguez, A., Guevara, J.L., Vidal, V., Diaz-Robles, L.A., Nicolas Schiappacasse, L., Etcharren, P., 2012. Obtaining polycyclic aromatic hydrocarbon concentration ratios and molecular markers for residential wood combustion: temuco, a case study. J. Air Waste Manag. Assoc. 62, 44-51.

Chellam, S., Kulkarni, P., Fraser, M.P., 2005. Emissions of organic compounds and trace metals in fine particulate matter from motor vehicles: a tunnel study in Houston, Texas. J. Air Waste Manag. Assoc. 55, 60-72.

Chen, D., Wang, X., Li, Y., Lang, J., Zhou, Y., Guo, X., Zhao, Y., 2017. High-spatiotemporal-resolution ship emission inventory of China based on AIS data in 2014. Sci. Total Environ. 609, 776-787.

Chen, D., Zhao, Y., Nelson, P., Li, Y., Wang, X., Zhou, Y., Lang, J., Guo, X., 2016. Estimating ship emissions based on AIS data for port of Tianjin, China. Atmos. Environ. 145, 10-18.

Chen, Y., Bi, X., Mai, B., Sheng, G., Fu, J., 2004. Emission characterization of particulate/ gaseous phases and size association for polycyclic aromatic hydrocarbons from residential coal combustion. Fuel 83, 781-790.

Chen, Y., Sheng, G., Bi, X., Feng, Y., Mai, B., Fu, J., 2005. Emission factors for carbonaceous particles and polycyclic aromatic hydrocarbons from residential coal combustion in China. Environ. Sci. Technol. 39, 1861-1867.

Choiseul, V., Wilson, J.G., Nixon, E., 1998. The distribution of hydrocarbons on the east and south-west Irish coasts and in the Liffey Estuary. In: Biology and Environmentproceedings of the Royal Irish Academy 98B. pp. 75-86.

Cooper, D., Gustafsson, T., 2004. Methodology for Calculating Emissions from Ships: 1. Update of Emission Factors. Swedish environmental research institute ordered by Swedish Environmental Protection Agency, Stockholm.

Cooper, D.A., 2003. Exhaust emissions from ships at berth. Atmos. Environ. 37, 3817-3830.

Cooper, D.A., Peterson, K., Simpson, D., 1996. Hydrocarbon, PAH and PCB emissions from ferries: a case study in the Skagerak-Kattegatt-Oresund region. Atmos. Environ. 30, 2463-2473.

Corbeet, J.J.F P. 1997. Emissions from ships. Science 278, 823-824.

Crimmins, B.S., Dickerson, R.R., Doddridge, B.G., Baker, J.E., 2004. Particulate polycyclic aromatic hydrocarbons in the Atlantic and Indian Ocean atmospheres during the Indian Ocean Experiment and Aerosols 99: continental sources to the marine atmosphere. J. Geophys. Res. Atmos. 109.

Czech, H., Schnelle-Kreis, J., Streibel, T., Zimmermann, R., 2017. New directions: beyond sulphur, vanadium and nickel - about source apportionment of ship emissions in emission control areas. Atmos. Environ. 163, 190-191.

Dai, S., Bi, X., Chan, L.Y., He, J., Wang, B., Wang, X., Peng, P., Sheng, G., Fu, J., 2015 Chemical and stable carbon isotopic composition of PM2.5 from on-road vehicle emissions in the PRD region and implications for vehicle emission control policy. Atmos. Chem. Phys. 15, 3097-3108.

De La Torre-Roche, R.J., Lee, W.-Y., Campos-Diaz, S.I., 2009. Soil-borne polycyclic aromatic hydrocarbons in El Paso, Texas: analysis of a potential problem in the United States/Mexico border region. J. Hazard Mater. 163, 946-958.

Diesch, J.M., Drewnick, F., Klimach, T., Borrmann, S., 2013. Investigation of gaseous and particulate emissions from various marine vessel types measured on the banks of the Elbe in Northern Germany. Atmos. Chem. Phys. 13, 3603-3618.

Donateo, A., Gregoris, E., Gambaro, A., Merico, E., Giua, R., Nocioni, A., Contini, D. 2014. Contribution of harbour activities and ship traffic to PM2.5, particle number concentrations and PAHs in a port city of the Mediterranean Sea (Italy). Environ. Sci. Pollut. Control Ser. 21, 9415-9429.

Duan, F., He, K., Liu, X., 2010. Characteristics and source identification of fine particulate n-alkanes in Beijing, China. JEnvS 22, 998-1005.

Endresen, Ø., Sørgård, E., Sundet, J.K., Dalsøren, S.B., Isaksen, I.S., Berglen, T.F., Gravir, G., 2003. Emission from international sea transportation and environmental impact. J. Geophys. Res. Atmos. 108.

Eyring, V., Isaksen, I.S.A., Berntsen, T., Collins, W.J., Corbett, J.J., Endresen, O., Grainger, R.G., Moldanova, J., Schlager, H., Stevenson, D.S., 2010. Transport impacts on atmosphere and climate: Shipping. Atmos. Environ. 44, 4735-4771.

Fan, Q., Zhang, Y., Ma, W., Ma, H., Feng, J., Yu, Q., Yang, X., Ng, S.K.W., Fu, Q., Chen, L., 2016. Spatial and seasonal dynamics of ship emissions over the yangtze river delta and east China sea and their potential environmental influence. Environ. Sci. Technol. 50, 1322-1329.

Finardi, S., Radice, P., Cecinato, A., Gariazzo, C., Gherardi, M., Romagnoli, P., 2017 Seasonal variation of PAHs concentration and source attribution through diagnostic ratios analysis. Urban Clim. 22, 19-34.

Fu, M., Ding, Y., Ge, Y., Yu, L., Yin, H., Ye, W., Liang, B., 2013. Real-world emissions of inland ships on the Grand Canal, China. Atmos. Environ. 81, 222-229.

Fu, Q., Shen, Y., Zhang, J., 2012. On the ship pollutant emission inventory in Shanghai Port. J. Saf. Environ. 12, 57-63.

Fuglestvedt, J., Berntsen, T., Eyring, V., Isaksen, I., Lee, D.S., Sausen, R., 2009. Shipping emissions: from cooling to warming of Climate and reducing impacts on health. Environ. Sci. Technol. 43, 9057-9062.

Gagosian, R.B., Peltzer, E.T., Zafiriou, O.C., 1981. Atmospheric transport of continentally derived lipids to the tropical north Pacific. Nature 291, 312-315.

Gagosian, R.B., Zafiriou, O.C., Peltzer, E.T., Alford, J.B., 1982. Lipids in aerosols from the tropical north Pacific - temporal variability. J. Geophys. Res. Oceans Atmos. 87, 1133-1144.

Gregoris, E., Barbaro, E., Morabito, E., Toscano, G., Donateo, A., Cesari, D., Contini, D., Gambaro, A., 2016. Impact of maritime traffic on polycyclic aromatic hydrocarbons, metals and particulate matter in Venice air. Environ. Sci. Pollut. Control Ser. 23, 6951-6959.

Gullett, B.K., Tabor, D., Touati, A., Kasai, J., Fitz, N., 2012. Emissions from open burning of used agricultural pesticide containers. J. Hazard Mater. 221-222, 236-241.

Hassellov, I.-M., Turner, D.R., Lauer, A., Corbett, J.J., 2013. Shipping contributes to ocean acidification. Geophys. Res. Lett. 40, 2731-2736.

Hays, M.D., Fine, P.M., Geron, C.D., Kleeman, M.J., Gullett, B.K., 2005. Open burning of agricultural biomass: physical and chemical properties of particle-phase emissions. Atmos. Environ. 39, 6747-6764.

Huang, C., Lou, S., Qiao, L., Jing, S.a., Tao, S., Zhou, M., Chen, C., 2016. Physicochemical characteristics of real-world PM emissions from heavy-duty diesel buses. Res. Environ. Sci. 29, 1352-1361.

Jin, T., Yin, X., Xu, J., Yang, L., Ge, W., Ju, M., 2009. Air pollutants emission inventory from commercial ships of Tianjin Harbor. Mar. Environ. Sci. 28, 623-625.

Jonson, J.E., Tarrason, L., Klein, H., Vestreng, V., Cofala, J., Whall, C., 2009. Effects of ship emissions on European ground-level ozone in 2020. Int. J. Rem. Sens. 30, 4099-4110.

Kasumba, J., Holmen, B.A., 2016. Nonpolar organic compound emission rates for lightduty diesel engine soybean and waste vegetable oil biodiesel fuel combustion. Energy Fuels 30, 9783-9792.

Katsoyiannis, A., Terzi, E., Cai, Q.-Y., 2007. On the use of PAH molecular diagnostic ratio in sewage sludge for the understanding of the PAH sources. Is this use appropriate.? Chemosphere 69, 1337-1339.

Lack, D.A., Corbett, J.J., 2012. Black carbon from ships: a review of the effects of ship speed, fuel quality and exhaust gas scrubbing. Atmos. Chem. Phys. 12, 3985-4000.

Li, C., Yuan, Z., Ou, J., Fan, X., Ye, S., Xiao, T., Shi, Y., Huang, Z., Ng, S.K.W., Zhong, Z. Zheng, J., 2016a. An AIS-based high-resolution ship emission inventory and its uncertainty in Pearl River Delta region, China. Sci. Total Environ. 573, 1-10.

Li, Z., Chen, L., Liu, S., Ma, H., Wang, L., An, C., Zhang, R., 2016b. Characterization of PAHs and PCBs in fly ashes of eighteen coal-fired power plants. Aerosol Air Qual. Res. $16,3175-3186$.

Li, Z., Fan, L., Wang, L., Ma, H., Hu, Y., Jiang, Y., An, C., Liu, A., Han, J., Jin, H., 2018 $\mathrm{PAH}$ profiles of emitted ashes from indoor biomass burning across the beijing-tianjin Hebei region and implications on source identification. Aerosol Air Qual. Res. 18, 749-761.

Liu, H., Fu, M., Jin, X., Shang, Y., Shindell, D., Faluvegi, G., Shindell, C., He, K., 2016. Health and climate impacts of ocean-going vessels in East Asia. Nat. Clim. Change 6, 1037-1041.

Liu, W.X., Dou, H., Wei, Z.C., Chang, B., Qiu, W.X., Liu, Y., Tao, S., 2009. Emission characteristics of polycyclic aromatic hydrocarbons from combustion of different residential coals in North China. Sci. Total Environ. 407, 1436-1446.

Liu, Z., Lu, X., Feng, J., Fan, Q., Zhang, Y., Yang, X., 2017. Influence of ship emissions on urban air quality: a comprehensive study using highly time-resolved online measurements and numerical simulation in Shanghai. Environ. Sci. Technol. 51, 202-211.

Moldanova, J., Fridell, E., Popovicheva, O., Demirdjian, B., Tishkova, V., Faccinetto, A., Focsa, C., 2009. Characterisation of particulate matter and gaseous emissions from a large ship diesel engine. Atmos. Environ. 43, 2632-2641.

Murphy, S.M., Agrawal, H., Sorooshian, A., Padró, L.T., Gates, H., Hersey, S., Welch, W. Jung, H., Miller, J., Cocker III, D.R., 2009. Comprehensive simultaneous shipboard and airborne characterization of exhaust from a modern container ship at sea. Environ. Sci. Technol. 43, 4626-4640.

Nguyen-Duy, D., Chang, M.B., 2017. Review on characteristics of PAHs in atmosphere, anthropogenic sources and control technologies. Sci. Total Environ. 609, 682-693.

Oanh, N.T.K., Albina, D.O., Ping, L., Wang, X.K., 2005. Emission of particulate matter and polycyclic aromatic hydrocarbons from select cookstove-fuel systems in Asia. Biomass Bioenergy 28, 579-590.

Pandolfi, M., Gonzalez-Castanedo, Y., Alastuey, A., de la Rosa, J.D., Mantilla, E., Sanchez de la Campa, A., Querol, X., Pey, J., Amato, F., Moreno, T., 2011. Source apportionment of PM10 and PM2.5 at multiple sites in the strait of Gibraltar by PMF: impact of shipping emissions. Environ. Sci. Pollut. Control Ser. 18, 260-269.

Peng, Z., Ge, Y., Tan, J., Fu, M., Wang, X., Chen, M., Yin, H., Ji, Z., 2016. Emissions from several in-use ships tested by portable emission measurement system. OcEng 116, 260-267.

Pengchai, P., Furumai, H., Nakajima, F., 2004. Source apportionment of polycyclic aromatic hydrocarbons in road dust in Tokyo. Polycycl. Aromat. Comp. 24, 773-789.

Perrone, M.G., Carbone, C., Faedo, D., Ferrero, L., Maggioni, A., Sangiorgi, G., Bolzacchini, E., 2014. Exhaust emissions of polycyclic aromatic hydrocarbons, n-alkanes and phenols from vehicles coming within different European classes. Atmos. Environ. 82, 391-400.

Pies, C., Hoffmann, B., Petrowsky, J., Yang, Y., Ternes, T.A., Hofmann, T., 2008. Characterization and source identification of polycyclic aromatic hydrocarbons (PAHs) in river bank soils. Chemosphere 72, 1594-1601.

Pietrogrande, M.C., Mercuriali, M., Perrone, M.G., Ferrero, L., Sangiorgi, G., Bolzacchini, E., 2010. Distribution of n-alkanes in the northern Italy aerosols: data handling of GCMS signals for homologous series characterization. Environ. Sci. Technol. 44, $4232-4240$. 
Ravindra, K., Sokhi, R., Van Grieken, R., 2008a. Atmospheric polycyclic aromatic hydrocarbons: source attribution, emission factors and regulation. Atmos. Environ. 42, 2895-2921.

Ravindra, K., Wauters, E., Van Grieken, R., 2008b. Variation in particulate PAHs levels and their relation with the transboundary movement of the air masses. Sci. Total Environ. 396, 100-110.

Riddle, S.G., Jakober, C.A., Robert, M.A., Cahill, T.M., Charles, M.J., Kleeman, M.J., 2007. Large PAHs detected in fine particulate matter emitted from light-duty gasoline vehicles. Atmos. Environ. 41, 8658-8668.

Russell, L.M., Noone, K.J., Ferek, R.J., Pockalny, R.A., Flagan, R.C., Seinfeld, J.H., 2000. Combustion organic aerosol as cloud condensation nuclei in ship tracks. J. Atmos. Sci. 57, 2591-2606.

Schauer, J.J., Kleeman, M.J., Cass, G.R., Simoneit, B.R.T., 2002. Measurement of emissions from air pollution sources. 5. C-1-C-32 organic compounds from gasolinepowered motor vehicles. Environ. Sci. Technol. 36, 1169-1180.

Schreier, M., Kokhanovsky, A.A., Eyring, V., Bugliaro, L., Mannstein, H., Mayer, B., Bovensmann, H., Burrows, J.P., 2006. Impact of ship emissions on the microphysical, optical and radiative properties of marine stratus: a case study. Atmos. Chem. Phys. 6, 4925-4942.

Shah, S.D., Ogunyoku, T.A., Miller, J.W., Cocker, D.R., 2005. On-road emission rates of $\mathrm{PAH}$ and n-alkane compounds from heavy-duty diesel vehicles. Environ. Sci. Technol. 39, 5276-5284.

Simcik, M.F., Eisenreich, S.J., Lioy, P.J., 1999. Source apportionment and source/sink relationships of PAHs in the coastal atmosphere of Chicago and Lake Michigan. Atmos. Environ. 33, 5071-5079.

Simoneit, B.R.T., 1989. Organic-matter of the troposphere. 5. Application of molecular marker analysis to biogenic emissions into the troposphere for source reconciliations. J. Atmos. Chem. 8, 251-275.

Sippula, O., Stengel, B., Sklorz, M., Streibel, T., Rabe, R., Orasche, J., Lintelmann, J., Michalke, B., Abbaszade, G., Radischat, C., Groeger, T., Schnelle-Kreis, J., Harndorf, H., Zimmermann, R., 2014. Particle emissions from a marine engine: chemical composition and aromatic emission profiles under various operating conditions. Environ. Sci. Technol. 48, 11721-11729.

Song, S., 2014. Ship emissions inventory, social cost and eco-efficiency in Shanghai Yangshan port. Atmos. Environ. 82, 288-297.

Song, Y., 2015. Research of Emission Inventory and Emission Character of Inland and Offshore. Ships Beijing Institute of Technology.

Srogi, K., 2007. Monitoring of environmental exposure to polycyclic aromatic hydrocarbons: a review. Environ. Chem. Lett. 5, 169-195.

Tobiszewski, M., Namiesnik, J., 2012. PAH diagnostic ratios for the identification of pollution emission sources. Environ. Pollut. 162, 110-119.

U.S. EPA. (United States, E.P.A), 1979. Water-related Environmental Fate of 129 Prioritypollutants. EPA Publication, Washington, D.C EPA-440/4-79-029a (Volume 1) and EPA-440/4-79-029b (Volume II). Office of WaterPlanning and Standards.

Vasconcellos, P.C., Souza, D.Z., Sanchez-Ccoyllo, O., Bustillos, J.O.V., Lee, H., Santos, F.C., Nascimento, K.H., Araujo, M.P., Saarnio, K., Teinila, K., Hillamo, R., 2010. Determination of anthropogenic and biogenic compounds on atmospheric aerosol collected in urban, biomass burning and forest areas in Sao Paulo, Brazil. Sci. Total Environ. 408, 5836-5844.

Viana, M., Hammingh, P., Colette, A., Querol, X., Degraeuwe, B., de Vlieger, I., van
Aardenne, J., 2014. Impact of maritime transport emissions on coastal air quality in Europe. Atmos. Environ. 90, 96-105.

Winebrake, J.J., Corbett, J.J., Green, E.H., Lauer, A., Eyring, V., 2009. Mitigating the health impacts of pollution from oceangoing shipping: an assessment of low-sulfur fuel mandates. Environ. Sci. Technol. 43, 4776-4782.

Xiao, Q., Li, M., Liu, H., Deng, F., Fu, M., Man, H., Jin, X., Liu, S., Lv, Z., He, K., 2018. Characteristics of marine shipping emissions at berth: profiles for PM and VOCs. Atmos. Chem. Phys. Discuss. 1-29 2018.

Xie, M., Wang, G., Hu, S., Han, Q., Xu, Y., Gao, Z., 2009. Aliphatic alkanes and polycyclic aromatic hydrocarbons in atmospheric PM10 aerosols from Baoji, China: implications for coal burning. Atmos. Res. 93, 840-848.

Yan, B., Zheng, M., Hu, Y.T., Lee, S., Kim, H.K., Russell, A.G., 2008. Organic composition of carbonaceous aerosols in an aged prescribed fire plume. Atmos. Chem. Phys. 8, 6381-6394.

Yang, H.H., Chien, S.M., Cheng, M.T., Peng, C.Y., 2007. Comparative study of regulated and unregulated air pollutant emissions before and after conversion of automobiles from gasoline power to liquefied petroleum gas/gasoline dual-fuel retrofits. Environ. Sci. Technol. 41, 8471-8476.

Yang, J., Yin, P.-1., Ye, S.-q., Wang, S.-s., Zheng, J.-y., Ou, J.-m., 2015a. In: Marine Emission Inventory and Its Temporal and Spatial Characteristics in the City of Shenzhen. Huan jing ke xue $=$ Huanjing kexue/[bian ji, Zhongguo ke xue yuan huan jing ke xue wei yuan hui "Huan jing ke xue" bian ji wei yuan hui, vol. 36. pp. $1217-1226$.

Yang, J., Yin, P., Ye, S., Wang, S., Zheng, J., Ou, J., 2015b. Marine emission inventory and its temporal and spatial characteristics in the city of shenzhen. Environ. Sci. 34 1217-1226.

Ye, S., Zheng, J., PAn, Y., Wang, S., Lu, Q., Zhong, L., 2014. Marine emission inventory and its temporal and spatial characteristics in Guangdong Province. Acta Sci. Circumstantiae 34, 537-547.

Yunker, M.B., Macdonald, R.W., Vingarzan, R., Mitchell, R.H., Goyette, D., Sylvestre, S., 2002. PAHs in the Fraser River basin: a critical appraisal of PAH ratios as indicators of PAH source and composition. OrGeo 33, 489-515.

Zhang, F., Chen, Y., Chen, Q., Feng, Y., Shang, Y., Yang, X., Gao, H., Tian, C., Li, J., Zhang, G., Matthias, V., Xie, Z., 2018. Real-World emission factors of gaseous and particulate pollutants from marine fishing boats and their total emissions in China. Environ. Sci. Technol. 52, 4910-4919.

Zhang, F., Chen, Y., Tian, C., Wang, X., Huang, G., Fang, Y., Zong, Z., 2014. Identification and quantification of shipping emissions in Bohai Rim, China. Sci. Total Environ. 497-498, 570-577.

Zhang, F., Chen, Y.J., Tian, C.G., Lou, D.M., Li, J., Zhang, G., Matthias, V., 2016. Emission factors for gaseous and particulate pollutants from offshore diesel engine vessels in China. Atmos. Chem. Phys. 16, 6319-6334.

Zhang, L., Zheng, J., Yin, S., Peng, K., Zhong, L., 2010. Development of non-road mobile source emission inventory for the pearl river delta region. Environ. Sci. 31, 886-891.

Zhang, Y.-x., Shao, M., Zhang, Y.-h., Zeng, L.-m., He, L.-y., Zhu, B., Wei, Y.-j., Zhu, X.-1., 2007. Source profiles of particulate organic matters emitted from cereal straw burnings. JEnvS 19, 167-175.

Zhao, M., Zhang, Y., Ma, W., Fu, Q., Yang, X., Li, C., Zhou, B., Yu, Q., Chen, L., 2013. Characteristics and ship traffic source identification of air pollutants in China's largest port. Atmos. Environ. 64, 277-286. 